\title{
REFLEXÕES SOBRE O HOMEM E O TRABALHO
}

\section{0}

ARTIGO
" Rubens Migllacclo Filho

Considerações filosóficas aliadas aos conhecimentos e experiências empresariais ampliam os horizontes da relação homem-trabalho.

Philosophical reflections joined to administrative knowledge and experience extend the horizons of the man-work relationship.

Homem, humanismo, trabalho, empresa, gerência, ética.

KEY WORDS:

Man, humanism, work, firm, management, ethic.

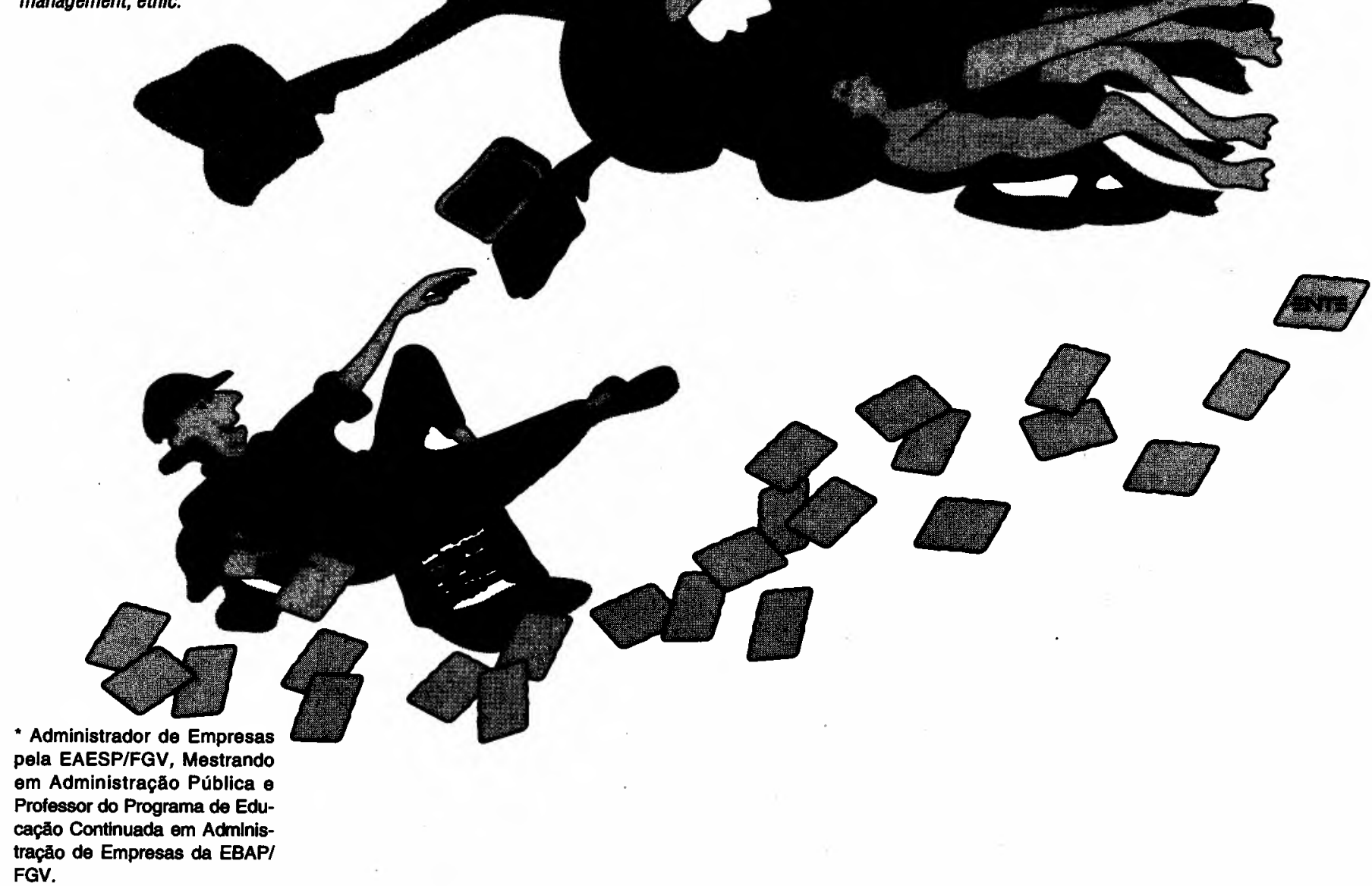


McGregor, no clássico The humam side of Enterprise, näo deixou dúvidas sobre a importância dos fatores humanos na atividade empresarial.

É fácil constatar que não trataremos de um tema inédito.

Além disso, nāo temos, pessoalmente, nenhuma pretensão de originalidade, pelo contrário, apresentamos nesse trabalho um conjunto de idéias que não são "propriamente" nossas, mas feitas próprias pela desconcertante profundidade com que nos foram apresentadas.

Desde que começamos a nos interessar pela literatura empresarial em 1979, não nos lembramos de termos lido algo tão marcante como os trabalhos elaborados pelo Instituto de Estudos Superiores da Empresa (IESE), e, nos últimos anos, pelo Seminário Permanente Empresa e Humanismo, que congrega a Faculdade de Filosofia e Letras e a Faculdade de Ciências Econômicas da Universidade de Navarra com empresas e instituiçöes como: IBM, Alcatel, Standard Eletric, Pirelli, Coca-Cola, Hidroeléctrica Española, entre outras.

Sobretudo, interessou-nos a forma de integrar uma sólida experiência empresaxial com conhecimentos e reflexões filosóficas, numa clara opção pelo ser humano frente aos desafios de uma sociedade que, com freqüência, subjulga o homem.

O fruto dessas considerações - aparentemente dispersas - poderá abrir novos horizontes para o exercício do trabalho humano: um olhar interior que ultrapassa o fazer para refletir sobre o fazer melhor, de um modo prático e realista.

\section{INTHODUCĀO}

Durante os anos 80 , o prestígio da ética subiu muitos pontos. Depois de uma série de escândalos, compreendese a urgência de revalorizar a ética dos negócios e de transmiti-la aos futuros managers. Tudo indica o nascimento de um novo humanismo. O homem que restou do fracassado projeto moderno precisa ser reconstruído a partir dos postulados de uma nova sensibilidade. Esse caminho é o que vem sendo trilhado no "Seminário Permanente Empresa e Humanismo", que reúne a Universidade de Navarra (Espanha), através do seu Instituto de Estudos Superiores da Empresa (IESE) - uma das cinco melhores escolas de negócios da Europa segundo a revista Fortune - com conhecidas empresas transnacionais como IBM, Pirelli, Coca-Cola, Nestlé, Xerox, Nixdorf, entre outras.

No programa de apresentação do Seminário, encontram-se as seguintes palavras: "A Empresa é uma instituição deci-

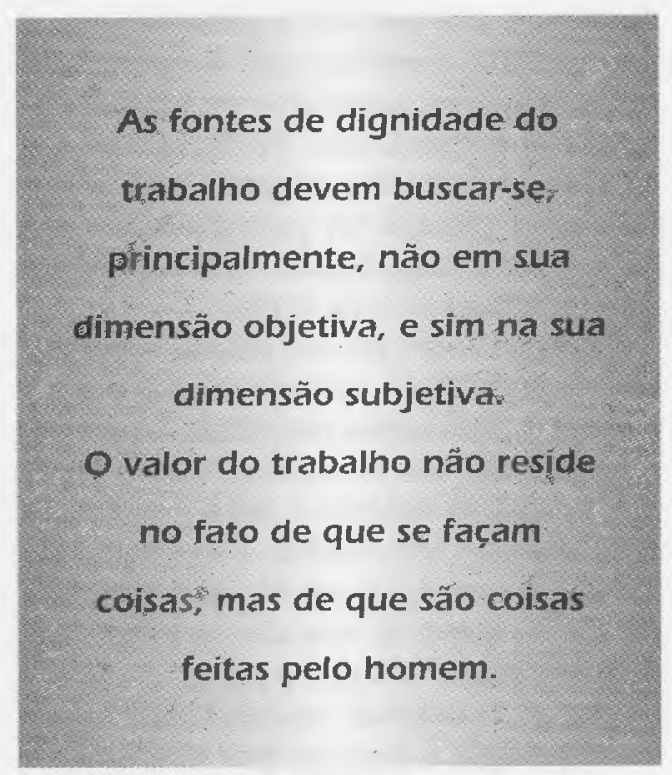

siva para o desenvolvimento econômico, para a dinamização da sociedade e a promoção das liberdades pessoais e públicas. Sua vitalidade expressa a criatividade da trama social e a capacidade dos cidadãos para enfrentar os desafios econômicos, sociais e culturais do presente momento. As raizes da capacidade de empreender se encontram na pessoa humana. Hoje já sabemos que os problemas mais importantes da Empresa não são os tecnológicos, e sim os antropológicos $e$ sociológicos. O atual dirigente empresarial não é só um expert em estratégia; tem que ser, sobretudo, um humanista capaz de conhecer com profundidade e rigor os homens $e$ as suas circunstâncias sociais". 1.

Este trabalho procura apresentar um pequeno mosaico do pensamento presente nesse Seminário e, principalmente, levar os dirigentes de recursos humanos a uma reflexão sobre a característica peculiar do objeto do seu trabalho: seles humanos.
1. LLANO, Carlos et al. La vertiente humana del trabajo en la empresa, Madrid: Rialp, 1990 
FUNDAMENTOS ANTROPOLÓGICOS: DISCUSSÕES A RESPEITO DO HOMEM

\section{O que é o homem}

Ocupar-nos do homem como ser vivente e racional, com história e com cultura é, sobretudo, responder o que é ser homem. A antropologia projeta-nos uma luz sobre essas indagações sem propriamente as responder. Várias concepções, por vezes contraditórias, foram elaboradas, procurando elucidar o fenômeno humano. A teoria do conhecimento e a metodologia da ciência nos ajudam a perceber que o pensamento científico está determinado por concepções, consciente ou inconscientemente defendidas. Poderíamos até afirmar que para dar origem a uma antropologia é preciso ter previamente uma concepção antropológica. A neutralidade do pensamento é uma ficção.

Gómez Pérez ${ }^{2}$, em seu estudo sobre antropologia política, assinala duas possíveis respostas para nossa pergunta: "A primeira: o homem é um ser natural, vivente superior, produto da Natureza e reintegrável ao natural orgânico, sem resíduo; a segunda: o homem é um ser natural, vivente superior, criado por Deus e dotado de uma alma que transcende imortalmente o natural orgânico". ${ }^{3}$

$O$ que se entende ordinariamente por antropologia - veja-se, por exemplo, o trabalho de Claude Lévi-Strauss ${ }^{4}$ em seu livro Antropologia Estrutural - está compreendido na primeira resposta. É a antropologia natural. A segunda concepção recebe o nome de antropologia filosófica.

Antes que possamos fazer uma escolha entre uma concepção ou outra, convém aprofundar-se em seus aspectos essenciais.

E possível formular algum juízo sobre o ser humano, incapaz de ser refutado?

O bom senso nos faz admitir que o homem tem limitações: não consegue chegar a tudo a que se propõe. $E$ ainda podemos dizer que há especialmente uma limitação que preocupa o ser humano como nenhuma outra: a temporalidade da sua existência, em outras palavras, a mortalidade do homem. É interessante observar que convive com essa comprovação de finitude uma aspiração a superar-se, a transcender-se. E o mistério e o fascínio da busca do sentido da vida. Surge, então, o impasse, e acaba o que poderia ser de consenso geral.
Ao responder pelo sentido da vida deste homem geramos diversas respostas que Gómez Pérez ${ }^{5}$ sintetiza em quatro possibilidades:

1. o sentido da vida individual, finita, é a própria vida finita e individual;

2. o sentido da vida é a totalidade da história, a imortalidade da espécie, o insondável do espirito humano;

3. o sentido da vida é a realização da pertinência do homem a um gênero - o humano - chamado a reconciliar-se com a Natureza material;

4. o sentido da vida individual é a união com Deus, na história e, depois da história, na eternidade.

Podemos distinguir claramente dois grupos nas respostas acima. As três primeiras implicam a negação do transcendente: Deus e a imortalidade do homem como realidade. Diferem na análise das dicotomias individualidade/comunidade e indivíduo/espécie que ao longo da história assumiram posturas agrupadas por Gómez Pérez ${ }^{6}$, como veremos a seguir.

\section{Antropologias da insuperável finitude individual}

Nascem de uma especial sensibilidade com o fenômeno vida: o movimento, 0 vir a ser, a impossibilidade de enquadrar o vivo em esquemas racionais e fixos... Modernamente, as possibilidades reais da ciência causaram certas derivações nestas posturas rumo ao positivismo.

\section{Antropologias políticas do homem- liberdade}

Estas antropologias devem sua origem e desenvolvimento a Kant. Na base das posturas de eminentes filósofos como Hegel, Marx, Comte, Husserl, Heidegger e outros estão os pressupostos kantianos. O mais importante - ou, ao menos, o mais permanente - é a superioridade que reconhece a razão prática, e, nela, o descobrimento autônomo da lei moral do homem.

A "Crítica da Razão Prática" leva Kant a postular a presença no homem da idéia do mundo, da alma e de Deus. Dessas idéias surgirá o que definia como liberdade criadora do homem no âmbito da imortalidade da espécie. A Razão é a reli- 
gião. O imperativo da moralidade é descoberto pelo próprio homem em si mesmo.

Antropologias do materialismo-dialético

Hegel é o primeiro filósofo que não simplifica a experiência humana no sentido metafísico, uma vez que inclui tudo num sistema que é, para ele, o próprio desenvolvimento do real: desde a vida vegetal à liberdade, da família à moralidade, do demoníaco ao mistério da Trindade, tudo está incluído nos afãs e nas vicissitudes do Espírito, que é o Espírito de cada homem e o Espírito de Deus.

Depois de Santo Agostinho, não se conhecia uma concepçāo semelhante de história como um único processo. No entanto, enquanto que o pensador de Hipona concebe a única história como a história do homem criatura de Deus, Hegel entende a história como história de Deus imanente ao mundo, já que sem o mundo Deus năo seria Deus.

O rico e complexo pensamento de Hegel gerou seguidores aparentemente opostos, classificados em direita e esquerda hegeliana, e propriamente esta última dará origem à antropologia materialista histórico-dialética.

Feuerbach começa a limpeza da escória espiritual hegeliana: o Espírito de $\mathrm{He}-$ gel nāo é outro que o espírito humano. Marx radicalizaria ainda mais as idéias de Feuerbach materializando o Espírito. A matéria feita homem tem um vir a ser dialético até a suprema reconciliação do homem com a ratureza, da liberdade com a necessidade.

Sinteticamente, a antropologia dialética materialista afirma que a existência do espírito depende da do corpo, sendo a natureza do homem matéria orgânica altamente evoluída como resultado da luta dos contrários. Só a luta dos contrários, que se excluem, tem caráter absoluto, como sucede com o movimento e a evolução; esta é a razão pela qual o materialismo deve ser dialético, isto é, deve negarse a reconhecer qualquer essência imutável das coisas.

\section{Antropologia liberal}

No âmbito das sociedades liberais costumam existir três correntes antropológicas, que têm como denominador comum o naturalismo. Gómez Pérez ${ }^{7}$ as denomi- na de otimista, pessimista e relativista. As três têm em conta o fazer-se histórico, o movimento social, porque superaram o fixismo do liberalismo-histórico. No entanto, diferem na interpretação desse movimento. A otimista sustenta que é sempre possível chegar a uma situação melhor que a anterior, já que há um progresso implícito no ser-homem, se ocorrerem determinadas condições sociais. Rousseau iniciou esta corrente: o homem é indefectivelmente bom quando encontra os pressupostos naturais do seu desenvolvimento.

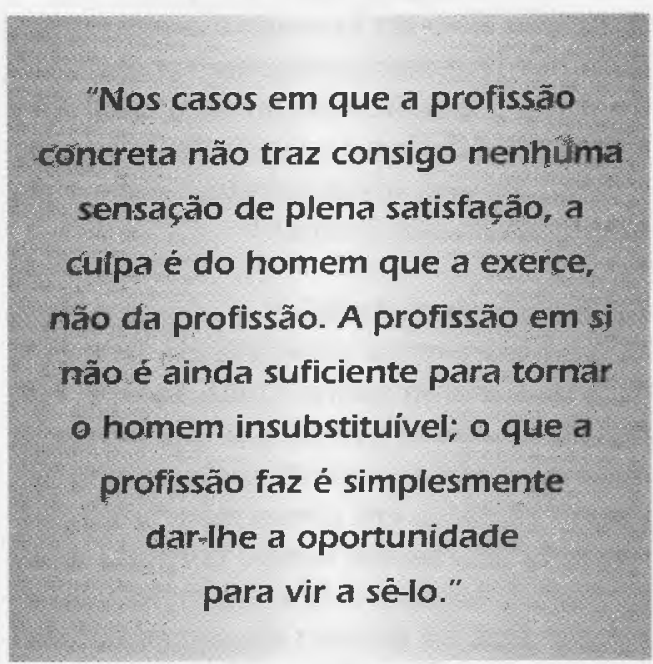

A antropologia pessimista sustenta que, por trás dos graves problemas sociais, observa-se uma possível regressão, quando não se previnem determinadas condições. A esperança sobre a perfeição da natureza humana é débil. A relativista não concede valor permanente aos termos progressão ou regressão, já que toma o presente como o único ponto de referência. Trata-se de uma antropologia resultante das duas anteriores e esconde um certo verniz de ceticismo frente às demandas sociais dos mais variados tipos.

$\mathrm{Na}$ análise empreendida até o momento, apenas consideramos três das quatro respostas relacionadas por Gómez Pérez. ${ }^{8}$ Passaremos, então, a analisar a quarta possibilidade: o sentido da vida individual é a uniăo com Deus, na história e, depois da história, na eternidade. Esta hipótese define um humanismo que denominaremos do homem-superior", composto por duas inseparáveis e complementares antropologias.
7. idem, ibidem p.177.

8. Idem, ibidem p. 181.

9. Idem, ibidem p. 181 
Antropologia empírica

A experiência da realidade humana colhida na natureza focaliza duas noções fundamentais: em primeiro lugar, o homem pertence ao reino animal pelo seu corpo, no entanto, representa uma espécie única em sentido zoológico, pois todas as "raças" humanas são capazes de se cruzarem ilimitadamente. ${ }^{10}$

A segunda noção que tomamos da antropologia empírica afirma que o homem é um ser provido de razão. O homem é homo faber, o único ser vivo que fabrica utensílios compreendendo a relação entre causa e efeito, graças à sua capacidade de abstração. Só o ser humano é capaz de determinar-se conscientemente na sua conduta. E o seu poder de conhecer e autodeterminar-se define-o como animal rationale et homo sapiens, distinguindo-o essencialmente do mundo animal. ${ }^{11}$

\section{Antropologia metafísica}

Ao penetrar na essência do homem, podemos extrair outras duas noções. Primeiro, o homem possui um espírito, algo que não é simplesmente matéria. Em segundo lugar, e em conseqüência da sua natureza ao mesmo tempo corporal e espiritual, o homem é um ser social, isto é, um ser que só no seio da sociedade encontra o seu pleno desenvolvimento.

A metafísica fundamenta-se na experiência, seguindo a convicção de que só cumpre metodicamente a sua missão quando for capaz de relacionar as suas conclusões com todo o domínio da realidade experimental concernente ao seu objeto. Sabemos que nenhuma metafísica poderia pretender resolver todos os seus problemas com uma certeza indiscutível. Não é menos certo que, qualquer metafísica que se feche parcialmente à experiência, tentando preterir o esclarecimento de fatos da realidade, cai em dogmatismos de algum tipo.

A antropologia metafísica sustenta que a alma humana é de natureza espiritual, livre e imortal, sendo também a sede da razão. Daí vem a distinção essencial entre corpo e espírito: o corpo é de natureza material, a alma, de natureza espiritual; nenhum dos dois pode se considerar uma resultante do outro. Em conjunto, ambos formam a unidade substancial da natureza humana, em que a alma é o princípio das ações especificamente humanas.

Incorporando os princípios do cristianismo sobre a natureza humana, a antropologia do homem-superior adquire a sua dimensão mais profunda.

Duas considerações são especialmente importantes: a primeira prende-se à realidade do pecado original, razão da possibilidade humana de errar, da perversidade da vontade e dos erros sucessivos que daí nasceram para a ordem da vida social. A segunda concerne ao fato do próprio Deus ter assumido a natureza humana para entrar no mundo, corroborando na alma do homem a semelhança com a divindade, a testemunhar que o valor da pessoa, com seu destino vinculado à alma espiritual - dignidade da pessoa - é superior a todo e qualquer valor terreno. Assim se explica que nem a sociedade, nem o Estado, nem a Nação, nem a raça, nem toda a criação se equiparam a esse valor.

\section{O HOMEM E O TRABALHO}

O trabalho, essencialmente, é uma ação própria do homem mediante a qual transforma e melhora os bens da nature$\mathrm{za}, \mathrm{com}$ a qual vive historicamente em insubstituível relação. Nesse sentido, podese afirmar que o homem trabalhou sempre e que não existirá momento, na terra, em que não será necessário trabalhar.

O primeiro fundamento do valor do trabalho é o próprio homem, seu sujeito, o trabalho está em função do homem e não o homem em função do trabalho.

Conseqüentemente, o fundamento para determinar o valor do trabalho não é o tipo de trabalho que se realiza, e sim o fato de que quem o executa é uma pessoa. As fontes de dignidade do trabalho devem buscar-se, principalmente, não em sua dimensão objetiva, e sim na sua dimensão subjetiva. O valor do trabalho não reside no fato de que se façam coisas, mas de que são coisas feitas pelo homem.

\section{O sentido do trabalho}

Considerando a antropologia do homem-superior, a que nos referimos anteriormente, podemos acrescentar a consciência que tem o homem de desempe- 
nhar na vida uma tarefa concreta e pessoal, derivada do seu caráter de algo único e irrepetível, uma missão.

O conteúdo dessa missão é duplo. Com efeito, a missão não muda apenas de homem para homem, em consonância com o caráter de algo único da pessoa. Muda também de hora a hora, em decorrência do caráter irrepetível de cada situação. Vejamos o que Scheler ${ }^{12}$ denominou "valores de situação". Estes valores funcionam como se estivessem à espera de que sua hora chegasse, à espera de que um homem aproveite a ocasião irrepetível de realizá-los, a ocasião que se deixa passar será perdida irremediavelmente e o valor da situação fica para sempre irrealizado - o homem desperdiçou-o.

As teorias de Planejamento Estratégico, desde os anos 60, destacaram a importância de uma empresa definir claramente a sua missão e atuar em conseqüência. Se isso é verdade para

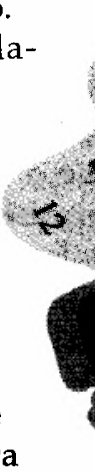
uma empresa, muito mais para o homem, que é a razão de ser de uma atividade empresarial.

Em particular, diz Frank1 13: "o trabalho pode representar o campo em que o "caráter de algo unico' do individuo se relaciona com a comunidade, recebendo assim o seu sentido e o seu valor. Contudo, este sentido e valor são inerentes, em cada caso, à realização (à realização com que se contribui para a comunidade) e não à profissão concreta como tal. Não é, por conseguinte, um determinado tipo de profissão o que oferece ao homem a possibilidade de atingir a plenitude. Nesse sentido, pode-se dizer que nenhuma profissão faz $o$ homem feliz. E, se há muitos, principalmente entre os neuróticos, que afirmam que se teriam realizado plenamente, caso tivessem escolhido outra profissão, o que se encerra nessa afirmação é uma deturpação do sentido do trabalho profissional ou a atitude de quem se engana a si mesmo. Nos casos em que a profissão concreta não traz consigo nenhuma sensação de plena satisfação, a culpa é do homem que a exerce, não da profissão. $A$ profissão em si não é ainda suficiente para tornar o homem insubstituivel; o que a profissão faz é simplesmente dar-lhe a oportunidade para vir a sê-lo".

Em outras palavras, o caráter insubstituível da vida humana, aquela impossibilidade do homem ser representado por outrem no que só ele pode e deve fazer, o seu "caráter de algo único" e irrepetível, a que temos nos referido, sempre depende do homem: não do que ele faz, mas de quem o faz e do modo como o faz.

\section{Evolução do Trabalho}

Se o trabalho, em sua essência, permanece inalterado, o tipo de trabalho, contudo, transformou-se e continua transformando-se ao longo da história. Da primitiva colheita e caça, do trabalho industrial para $o$ pós-industrial, as mudanças foram tão significativas que dificultam prever os novos rumos.

Em qualquer caso, haverá trabalho, mesmo que seja simplesmente organizar o ócio.

A modernidade recusa a idéia clássica de que a contemplação, a teoria - o simples olhar desinteressado - seja a mais alta atividade humana. A teoria é privada da sua posição dominante, para ser reduzida a uma função problematizadora e crítica, quase sempre negativa.

Ao perder a capacidade de distinção e orientação da teoria, as diversas atividades tendem a confundir-se entre si, a reduzirem-se em atividade transformadora do mundo físico: a técnica, o trabalho produtivo.

Certamente, a técnica moderna é uma das mais fascinantes conquistas da humanidade. A sensatez não nos permite imaginar o retorno a um mundo bucólico, pré-tecnológico.

Portanto, não se trata de prescindir da técnica e sim discutir a validade de tomá-la como algo absoluto, que pode obscurecer outras capacidades do homem empobrecendo a qualidade da vida humana.
12. SCHELER, Max. Ética material de los valores, In: DERISI, Octávio. Crítica filosófica, Madrid: E.M.E.S.A., 1979, p. 6180.

13. FRANKL, Victor E. Psicoterapia e o sentido da vida. São Paulo: Quadrante, 1986, p.160. 
14. Baseado nas idéias de LLANO, Carlos, Op. cit., p. 15-32.
Sobretudo, há um esquecimento prático da prudência, a capacidade de compreender sabiamente as circunstâncias concretas da vida e, como conseqüência, de agir de um modo ético. A técnica sem prudência se converte em poder incontrolado que pode ser utilizado para o bem ou para o mal, a favor ou contra o homem.

Esta redução antropológica, este estreitamento do horizonte humano, acabou por conduzir também a um empobrecimento da técnica, que perdeu seu impulso criativo e sua capacidade de resolução dos autênticos problemas sociais. A rigidez e a insuficiência do modo moderno de pensar e trabalhar requisitam uma superação.

As tarefas gerenciais e operacionais: um enfoque humanista ${ }^{14}$

$O$ conceito de empresa sofreu um giro diametral nos últimos anos. A empresa era definida como uma estrutura de capital, organização e trabalho para a consecução de um fim árduo. Trata-se de uma definição causal que apresenta implicitamente um conflito entre o capital e o trabalho. O capital era o mais importante e se distinguia do trabalho como um elemento estrutural, mas diverso ou estranho ao próprio trabalho.

A organização não objetivava coordenar o trabalho e o capital, para converter a estrutura num organismo. Sua aspiração era menor: tratava-se simplesmente de que a força de trabalho estivesse ordenada para obter os fins do capital.

A organização era o indicativo de como o capital determinava o modo de trabalhar: organizar era impor ou dispor, por parte do capital, a forma de trabalho. Marx apontou com razão - considerando esse aspecto analítico - que eram os trabalhadores que deveriam organizar-se, pois o capital não constituía o fator da empresa mais apropriado para fazê-lo: o capitalista, por definição, não era um trabalhador.

\section{As transformações na dinâmica interna da empresa}

Nos últimos vinte anos, estamos assistindo a importantes transformações na dinâmica interna da empresa. O capital passou a ser o fornecedor dos ins- trumentos de trabalho no seu sentido mais amplo, o que proporciona ao trabalho todo o ingente conjunto de condições externas para poder exercer sua ação transformadora no mercado, e sustentar os trabalhadores até que o ciclo renda as conseqüências econômicas pretendidas.

Nessa estrutura, o capital continua sendo imprescindível, e até mais do que antes, mas não como caput, e sim como instrumento a serviço objetivo do trabalho, qualquer que seja a intenção subjetiva do capitalista.

A organização já não se entende como alheia ao trabalho, ou dominadora dele, mas como resultado de um trabalho, ou uma modalidade de trabalho: o trabalho gerencial.

A empresa é compreendida, então, como um conjunto de trabalhos gerenciais e de instrumentos que o facilitam. $\mathrm{O}$ sinal que distingue o trabalho gerencial é o fato de não apresentar regras fixas e produzir resultados incertos. Em contraposição, o trabalho operacional é aquele que segue regras fixas e conhecidas e apresenta resultados, pelo menos, estatisticamente seguros. Nos dois casos, não estamos diante de uma definição essencial ou causal, e sim diante de características diferenciais de um tipo ou outro de trabalho. Pensando na relação entre trabalho gerencial e operacional, a filosofia nos leva a uma consideração mais profunda. Uma vez diferenciadas as naturezas daudireção ou gerência e da operação, a tendência administrativa tem sido também separar os que dirigem dos que operam, em outras palavras, que uns sejam os gerentes e outros os operadores. Evidentemente, essa distinção ou classificação de pessoas desconsidera o que a filosofia conseguiu saber sobre o homem.

Quando o homem é somente operador, isto é, quando não trabalha conforme as regras fixadas por ele mesmo ou assumidas como próprias, seu trabalho não se distingue do animal, que se conduz atavicamente por forças naturais, mas estranhas, no sentido de impostas, $e$ inclusive compulsivas. A separação de diretores e operadores poderá animalizar os segundos em favor dos primeiros. O trabalho gerencial se assemelha, nestas 
circunstâncias, à domesticação. Em contrapartida, quando o homem é apenas gerente, tampouco trabalha como homem, porque impõe uma regra, normalmente a sua própria, sem que tenha regra a que submeter-se. Mais do que um gerente é um semi-deus.

O exclusivo papel operacional faz o homem perder sua condição de racional, e o mesmo exclusivismo no papel gerencial pretende libertar o homem de sua condição de criatura com limites impostos pela sua própria natureza.

O trabalho de controle

Não podemos ignorar o prejuízo antropológico causado nos indivíduos quando separamos do seu agir dois aspectos que o integram essencialmente. É como dividir o próprio homem. A consciência do custo antropológico que acarreta essa divisão está ligada à consciência do custo utilitário: menor confiança e envolvimento por parte dos executores, imperícia executiva por parte dos planejadores, surgimento de um antagonismo mútuo entre os dois grupos, situação disjuntiva, segundo a qual uns ganham e outros perdem.

Este custo utilitário tem uma consequêencia relevante para a organização. No meio do trabalho gerencial, que assinala as regras, e do trabalho operacional, que procede conforme as regras assinaladas, aparece, necessariamente, o trabalho de controle que procura fazer com que os operadores se comportem conforme as indicações do gerente.

À medida que o operador se faz mais homem, mais racional, adquire capacidade para questionar as regras assinaladas e pôr à prova a sua validade. $O$ gerente não hesitará, a fim de manter a desejável ou inevitável separação dos trabalhos, em convocar os trabalhadores de "colarinho branco"com o inconveniente de que o controle não é produtivo por si mesmo: não deve confundir-se o contar o produzido, com produzir o que se conta. Desta forma, a organização do trabalho gera uma năo desejada qualificação de pessoas: os gerentes, os operadores e os controladores, os quais, por força do antagonismo antes mencionado, consideram-se uns aos outros sábios, párias e espiões.

\section{A divisão dos trabalhos e a divisão do trabalho}

Uma pergunta poderia ser feita nesse momento: como reparar o prejuízo antropológico causado pela separação das tarefas?

Llano ${ }^{15}$ nos esclarece ao afirmar que a natureza distinta da direção e da operação não implica necessariamente que sejam praticadas por pessoas diferentes. Pois, por mais controles que se estabeleçam, os operadores acabarão por exercer

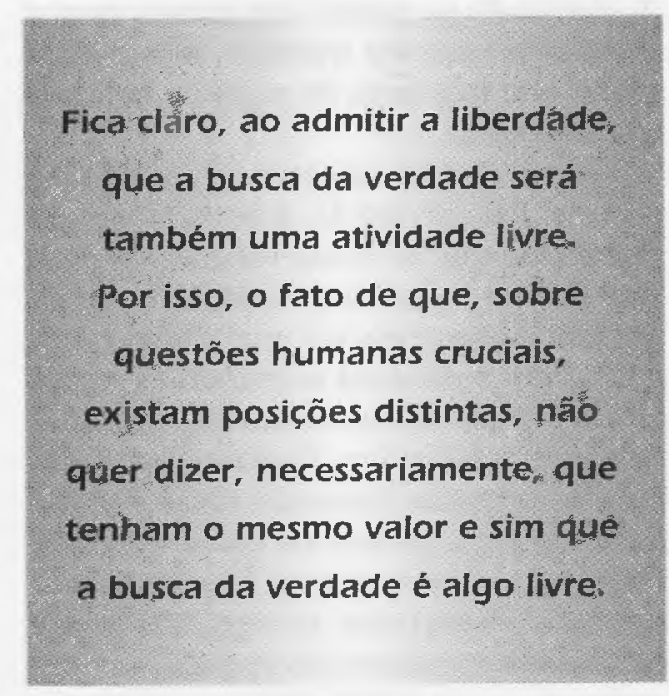

algum tipo de função gerencial, isto ć, cs tarão deixando a sua marca pessoal num trabalho, aparentemente, só operacional. Além disso, por mais que um gerente procure encastelar-se na sua torre de marfim, terminará mistificando a gerência com trabalhos operativos múltiplos. Se é inevitável, às vezes, sob certos aspectos mencionados, separar o gerencial do operacional, por força da organização, também é inevitável, por força da estrutura do ser humano, que essa separação conviva com uma mescla de ambos os tipos de trabalhos, seja querida ou não, desejada ou não, desde o ponto de vista estritamente administrativo e tecnológico.

Poderíamos dizer que não existem só dirigentes, nem só operadores, mas que todos dirigem e operam em seu nível. $O$ trabalhador como homem deve exercer ambas dimensões do trabalho.

Como ainda adverte Llano ${ }^{16}$, "a divisão dos trabalhos, necessária para a eficaz dinâmica da sociedade, não nos autoriza a divisão do trabalho, que constitui a alienaçāo radical.
15. LLANO, Carlos. Op. cit. p. 28 16. Idem, ibidem, p. 28-9 
Esta não se realiza, como dizia Marx, quando o homem se projeta em seu produto e se subtrai ao convertê-lo em mercadoria. A alienação radical tem lugar quando se despoja o trabalho - pelo sistema ou pela organização - de sua dimensão gerencial. Porque o gerenciamento é a expressão da autonomia pessoal no trabalho, é reflexo de sua racionalidade, da qual o homem, em momento algum, poderia ser despojado".

Há, no entanto, uma outra forma de reintroduzir o gerenciamento no trabalho operacional, mantendo sua distinção: não só alentando na pessoa um espaço para a autodireção do seu trabalho, mas procurando que faça suas as regras a que terá que sujeitar-se.

Não necessariamente a melhor idéia é a própria. Pelo contrário, a prática tem demonstrado que as idéias vencedoras derivam de un trabalho de equipe, onde intervêm muitas pessoas que sabem ceder nos critérios pessoais aceitando as regras indicadas por outro, na medida da racionalidade que contêm. Podemos acrescentar uma segunda dimensão na análise anterior, quando pensamos que a adesão a uma regra se encontra em função da consonância pessoal com as regras do jogo, e esta última consideração aponta para um maior domínio antropológico que tecnológico: o desenvolvimento de uma organização não se polarizará na busca e aplicação de sistemas operacionais adequados, mas, também, no crescimento da inteligência e da prudência das pessoas para que tenham a capacidade de fazê-los próprios, influenciando a natureza, desenho ou composição do sistema, que devem configurar atendendo à sua conexão técnica e também à possibilidade de ser apropriável por aqueles que devem operá-lo. Os operadores são pessoas concretas, dotadas de uma psique individual e de uma conformação moral determinada. A regra ou sistema, todo o aparelho organizativo da empresa, não é um mero assunto da tekné, e sim do ethos, do modo humano de ser da própria empresa.

\section{A DIMENSÃO ÉTICA DO TRABALHO NA EMPRESA}

17. CINTRA, Jorge P. Adaptada do livro Evolucionismo, mito e realidade, São Paulo: Quadrante, 1988, p. 4-5. posição decorrente da ruína dos sistemas de valores criados e cultivados pelo modernismo. Nos últimos decênios, estamos assistindo a grandes desilusões fáusticas. Desaparece gradualmente a confiança cega na técnica, no progresso sem limites. Esfumaça-se a esperança firme na história e na ciência. Igualmente se volatiza a fé no poder ilimitado de uma razão capaz de construir a sociedade perfeita. $\mathrm{O}$ doutor Fausto, símbolo goethiano de uma modernidade que não duvidava em pactuar com o demônio com o intuito de saciar sua sede de sabedoria e de domínio sobre o homem, agora se encontra desorientado, sem horizontes para as suas antigas motivações.

Não é estranho que, diante dos perigos que trazem consigo um desenvolvimento selvagem da modernidade e do progresso, exista quem tente propor uma norma reguladora nos diversos campos do comportamento humano, uma espécie de pacto social que garanta a estabilidade frente às conseqüûncias não desejadas de um comportamento pessoal e social irresponsável.

Podemos perguntar-nos: qual é o fundamento dessa espécie de pacto social? Poderemos denominá-lo de ética?

E tarefa urgente aprofundar no próprio conceito de ética, uma vez que é lugar comum rotular posturas limites sem uma maior reflexão sobre as mesmas. Por exemplo, tradicional e progressista, liberal e conservadora, direita e esquerda... A esse pretexto caberia reproduzir uma estorieta ${ }^{17}$ que pode nos ajudar a raciocinar analogicamente:

Um garoto assiste todas as tardes a filmes de faroeste, e, quando chega uma visita, pergunta-lhe imediatamente: "Você é mocinho ou bandido?" Perplexa com a situação de "beco sem saída"a visita reflete um pouco e responde com uma ponta de ironia: "Olha meu filho, eu moro em outro país, nasci 200 anos depois e simpatizo com os indios."

Em outras palavras, a realidade é muito mais rica do que os rígidos esquemas analíticos, e deve ser respeitada se quisermos evitar um lamentável reducionismo da natureza humana.

$O$ ético é algo que tem a ver com valores e tem sentido quando se pode recomendar que alguns valores sejam mais 
adequados que outros, para compor o comportamento. Mas isto seria insustentável, se partíssemos do princípio de que a verdade é algo só e exclusivamente subjetivo. Por isso, a primeira e fundamental questão a ser respondida no estudo da ética é a da possibilidade da verdade.

\section{A verdade possível}

O homem é um ser histórico e se, por vezes, assistimos a história condicionando o homem, não podemos ignorar que é o homem quem faz a história, isto é, há uma escolha de realização dentro de um sistema de exigências e possibilidades que lhe é dado. ${ }^{18}$

Os homens vivem num mundo e podemos defini-lo "como um sistema de crenças ordenadas numa perspectiva coerente" 19 . Por um lado, essa definição tem o caráter de clausura pela índole sistemática e total, por outro, o aspecto da liberdade do homem imprime nesse mundo um caráter essencialmente aberto. Falar do homem é falar de pretensōes que podem ou não realizar-se.

O sistema de vigências que constitui o mundo faz com que o homem saiba a que se ater, a respeito da sua situação, naquilo que ela tem de estável; diante dos problemas que essa situação propõe a cada instanle, o homem reage vivendo, isto é, com sua própria ação vital, que é a solução normal e primária dos problemas.

Esse sistema, entretanto, apresenta fissuras e, com certa freqüência, o homem sente-se perplexo e inseguro em relação a alguma coisa. A conseqüência imediata é que não saberá a que se ater diante dessa situação e surge nele a necessidade vital de algo que não possui e que podemos denominar verdade.

As fissuras na mundivivência do indivíduo são geradoras de incerteza ou do não saber a que se ater. Se essas fissuras não existissem, e o homem estivesse sempre esclarecido sobre sua situação, não necessitaria da verdade.

Quando lemos no jornal "Toda a verdade sobre o caso de Paulo César Farias e o ex-presidente Collor", temos a intenção de inteirar-nos do que aconteceu na

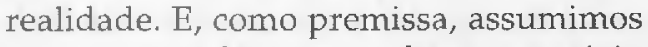
que o jornalista que fez a matéria conhece a verdade e está capacitado para contá-la. É um fato que "funciona- mos"continuamente com a verdade. Ninguém quer ser enganado ou, como diz o ditado popular, comprar gato por lebre. Pode-se vislumbrar que a verdade completa seja praticamente impossível. Ordinariamente chegamos a uma certa composição gradual, mais ou menos calculável, de verdade.

Há coisas e situações cuja verdade provisória e contingente nos satisfaz porque nos basta para seguir vivendo, para sabermos a que nos ater. Há outras situa-

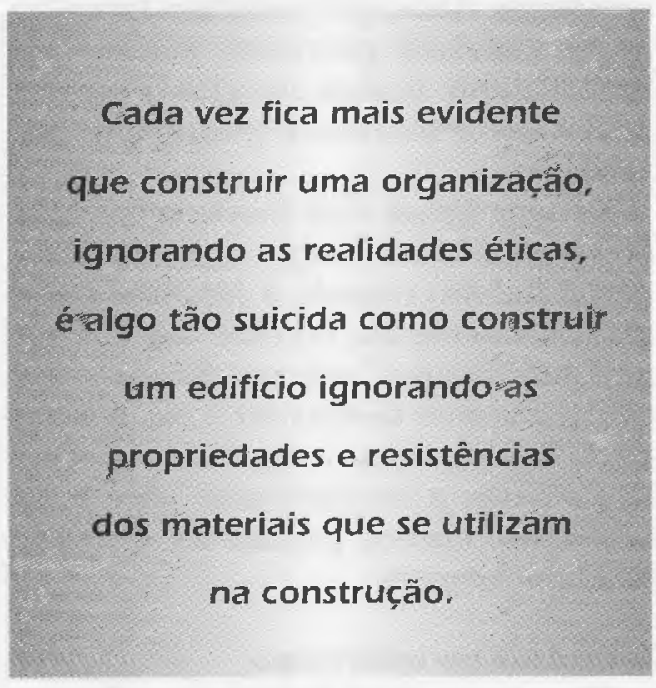

ções, nas quais não utilizamos o conceito de verdade porque são temas que variam conforme o gosto do indivíduo. Alguém poderia refutar a afirmação: "o abacaxi é uma fruta deliciosa"; pela simples razāo de achá-la demasiadamente ácida, portanto, nada deliciosa. Há poucas verdades sobre o gosto. Além disso, grande parte das coisas em que o gosto intervém passa por verdadeira em determinadas épocas, por uma questão circunstancial, um modismo.

\section{A verificação científico-experimental}

Não faz muito tempo, a Ciência era detentora das verdades definitivas e irreformáveis. A filosofia da Ciência acabou com esse mito. As ciências experimentais - aquelas que habitualmente são citadas quando se fala de Ciência avançam entre incertezas e provisoriedades. As verdades provisórias năo deixam de ser verdades e demonstram sua eficácia quando são aplicadas. Porém, não há um. cientista sério que sustente -
18. MARIAS, Julian. Introdução à filosofia. São Paulo: Duas cidades, 1966, p. 116-32.

19. Idem, ibidem, p. 129 
20. GÓMEZ PÉREZ, Rafael. Introdución a la ética social. Madrid: Rialp, 1988, p. 22.

\section{Idem, ibidem, p. 23}

22. MARIAS, Julian. Op. cit., p.121. como era pensamento comum no século XIX - que o homem conseguiu resolver os enigmas do Universo.

O fato de que os resultados das ciências foram e são úteis à humanidade, não é um critério de verdade absoluta. As ciências conduzem às verdades, mas provisórias e incompletas, sem deixar de serem verdades.

Algo semelhante ocorre no âmbito das ciências sociais, da história, da economia, da sociologia e outras mais diretamente ligadas ao estudo do homem. Existem constantes claras que permitem formular juízos e arriscar previsões. Porém, fica mais patente nessas ciências o caráter provisório e sobretudo incompleto das verdades.

De uma forma vital funcionamos com o esquema de verificação: algo nos parece verdadeiro quando a hipótese pode ser confirmada ou, no dizer de K. Popper, quando algo "pode suportar, sem cair, as tentativas de demonstrar a sua falsida$d e^{\prime \prime 20}$. Entra em cena a especial relevância que adquire a tangibilidade. Algo seria verdadeiro quando pudesse ser expresso de forma tangível.

\section{A verdade e o relativismo}

Vimos que, nem sequer nas ciências que mais controlamos, podemos falar de verdades completas e definitivas. Seguindo a mesma linha de raciocínio, não é difícil concluir que mais incompletas e mais imperfeitas e não definitivas serão as verdades daqueles temas cuja tangibilidade seja mais obscura e não se possa apalpar. As perguntas essenciais sobre o homem não seriam tema para uma verdade e sim para distintas e contrapostas opiniões.

No entanto, existem argumentos contrários a essas conclusões, que analisaremos a seguir: ${ }^{21}$

- alguns temas como a liberdade, a imortalidade, a existência do absoluto preocuparam e seguem preocupando o homem como realidades de outra ordem, mas realidades, com as quais haveria algo a fazer;

- esses temas são de tal modo cruciais que deles dependem atitudes e comportamentos que têm repercussões em quase todos os âmbitos da vida;
- por que a verdade estaria proibida a esses temas se nos demais campos, ainda que de maneira incompleta $e$ imperfeita, chega-se à verdade? Se a verdade é possível em muitos campos da experiência humana - e de fato "funcionamos" com ela - por que a investigação seria interrompida num determinado ponto, precisamente nos problemas de maior envergadura? Em qualquer caso, fica claro, ao admitir a liberdade, que a busca da verdade será também uma atividade livre. Por isso, o fato de que, sobre questões humanas cruciais, existam posições distintas, não quer dizer, necessariamente, que tenham o mesmo valor e sim que a busca da verdade é algo livre.

Considerando esse raciocínio, qual é a resposta para a pergunta: isso é verdade para você, mas será para mim? Em outras palavras, a verdade é relativa?

A postura de quem afirma que algo é verdadeiro para um e não verdadeiro para outro poderá ser válida quanto à liberdade da busca da verdade. Mas, não é válida se existe a pretensão de que algo possa ser, ao mesmo tempo, verdadeiro e falso. Com esse critério não "funcionamos" nunca, nem na vida real, nem na atividade científica. $O$ relativismo - a verdade depende de cada atitude, segundo cada qual a veja - não se sustenta.

Julian Marias ${ }^{22}$ define a realidade como tudo aquilo que encontra-se e tal como se encontra e seu modo próprio de ser é estar oculta. "É função da verdade pôr a descoberto o que as coisas são, transcender toda a mera aparência e desvelar a própria realidade, arrancar o homem da sua subjetividade, do círculo mágico de suas impressões ou idéias para colocar à sua frente as próprias coisas, e permitir, desse modo, que ele saiba a que se ater, como tudo isto é função da verdade, o relativismo anula, se não a 'essência', pelo menos alguma coisa que lhe seria ainda mais penoso se ele fosse conseqüente consigo mesmo: a função vital da verdade. Com efeito, 'minha' verdade não me basta e para que ela seja efetiva e realmente 'minha', para que eu possa aderir a ela e nela me apoiar, é necessário que não seja 'minha'e sim das coisas". 
Os reducionismos éticos e o formalismo moral

Sem uma adequada definição de verdade não se pode esperar uma postura ética consistente. É freqüente encontrar entre os autores que escrevem sobre Business Ethics ${ }^{23}$ - de um modo especial nos Estados Unidos - um enfoque pragmático, uma carta de intenções com certas regras do que a empresa deve fazer, ou deixar de fazer.

Em muitos casos, o critério decisivo para considerar uma decisão como ética ou não é determinado pela "aceitabilidade social" das consequêencias dessa decisão. À exceção de certos casos em que ingenuamente se supõe estar perfeitamente claro o conceito de socialmente aceitável, grande parte da discussão está centrada precisamente nesse ponto: a análise da "aceitabilidade social", sem uma avaliação da eticidade da decisão em si.

Por estas razões, as colocações intelectualmente mais rigorosas buscam sustentação nos postulados kantianos, aplicando o imperativo categórico e os princípios da Razão Prática, bem ao gosto norte-americano.

O produto final dessas elaborações consiste num conjunto de "regras éticas", e a maior parte do trabalho dos especialistas concentra-se em como aplicá-las nas situações concretas. Essa aplicação não é fácil.

O enfoque - com independência da racionalidade ou verdade das regras abstratas que com ele obtenham - tem duas limitações intrínsecas que podem invalidar sua utilidade prática . É o que observa a seguir López: ${ }^{24}$

"A primeira dessas limitações se refere aos motivos que levariam um gerente a aceitar a norma que the é proposta. Mesmo que essa norma buscasse garantir o valor social das decisões, em nenhum momento se lhe explica porque deve aceitá-la, quando é possível não fazêe-lo.

A consciência dessa debilidade leva não poucos teóricos a sustentar que as regras por eles deduzidas deveriam ser objeto de imposição coercitiva, via legal. Será interessante ver em que termina todo esse processo social porque, uma vez mais, vamos assistir à velha tragédia de uns intelectuais bem intencionados advogando - sem ser conscientes disso - a tirania, em nome do bem comum.
O problema de fundo é que, ao fixar-se uni camente no valor social (o valor para os outros) das ações com valor ético (o valor para o próprio decisor), prescinde-se de fato da Ética, optando por uma sociologia normativa sem fundamentação ética. A partir desse ponto, o que sucede não será mais que uma aplicação do velho teorema: da mesma forma que não pode haver Ética sem Liberdade, não é possível, tampouco, existir Liberdade sem Ética.

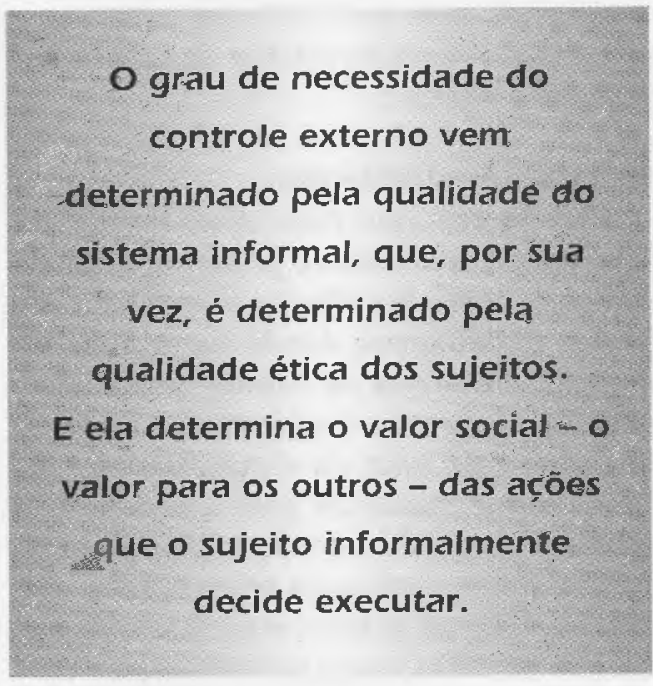

A segunda frente de limitações refere-se à possibilidade de previsāo, a priori, das distintas consegüêricias de uma ação. Assim, como a primeira limitação afeta um problema motivacional do decisor, esta afeta um problema cognoscitivo. Em síntese, o problema é o seguinte: a previsão das consequiências extemas de uma açāo - suscetiveis de observação empírica - é impossível quando na execução da ação intervêm decisores humanos. Somente seria possível se existissem as seguintes condiçöes:

- o previsor tem informação perfeita das regras de decisão que usarão todos e cada um dos decisores;

- essas regras de decisāo não se alteram com a atuação dos decisores, isto é, não há aprendizagem no decorrer das decisōes.

É evidente que, salvo casos triviais, qualquer avaliação de uma açäo baseada na previsāo de suas consequências externas - e observáveis - será nāo só incompleta, como nada impede que seja absolutamente errada.

A avaliação, a priori, das açōes humanas é o eixo de qualquer elaboração normativa sobre o comportamento humano. Uma avalia-
23. LÓPEZ, J. A. Pérez. La vertente humana del trabajo en la empresa. Madrid: Rialp, 1990, p. 36.

24. Idem, ibidem, p. 37-9. 
ção que pretenda fundamentar-se sobre as previsões das conseqüências externas dessas ações - como é o caso do enfoque que nos ocupa - está supondo uma teoria da decisão humana reducionista: ignora toda a delicada articulação do conhecimento humano no processo decisório.

O pior é que, além de reducionista é perigosa, pois está fechada ab initio à avaliação especificamente ética das ações humanas, uma vez que o valor ético de uma ação não depende de suas consequiências externas, $e$ sim das que causa no interior do próprio sujeito que a realiza."

\section{As raízes das limitações}

Percebemos que estas duas limitações têm uma dupla raiz. A primeira - e mais danosa - vem da redução ética a seus aspectos sociológicos, dando lugar a elaborações normativas de caráter sociológico, sem um autêntico fundamento ético. A segunda raiz vem da simploriedade do modelo que manipula para a decisão humana. Falta fundamento antropológico. Juntas, geram enfoques equivocados que não ajudam, na prática, o exercício da ética. Por um lado, cai-se no formalismo moral que não passa de uma classificação abstrata de ações humanas corretas ou incorretas, lícitas ou ilícitas, que não explica o porquê da validade do esforço para obter um ideal ético, ou mesmo, o que motivaria um indivíduo a decicir pela ética.

Faz falta mostrar, do modo mais prático possível, as conseqüências que o próprio sujeito padecerá ou desfrutará segundo a qualidade ética das suas ações. É tarefa importante da própria ética a busca de conclusões que permitam dar conteúdo empírico ao que significa para uma pessoa a carência ou a posse de qualidades morais. Abster-se dessa tarefa é dar um tratamento unidimensional para uma realidade tridimensional. Implica um modo de fazer ciência que aborda separadamente a elaboração de critérios de racionalidade ética - o homem ético - de racionalidade sociológica - o homem social - e de racionalidade econômica - o homem econômico.

\section{O gerente e a dimensão ética}

O outro lado da questão passa pela abordagem incompleta do que podería25. Idem, ibidem, p. 46. ao deficiente conceito de empresa a que já nos referimos ao tratar do trabalho gerencial e operacional: a empresa como um conjunto de pessoas que se esforça para conseguir, apenas, algum fim com valor econômico.

Com uma definição tão elementar e abstrata não podemos conseguir chegar ao parâmetro ético essencial: o que é ser um bom gerente?

Para podermos deduzir quais são as decisões próprias de um gerente enquanto tal, necessitamos de uma teoria autêntica sobre a empresa, porque as descrições das funções gerenciais depende da Teoria da Organização que se utilize para deduzi-las. Por outra parte, qualquer teoria implica - ou se fundamenta - uma concepção antropológica.

É interessante notar que este enfoque é essencialmente distinto do que se aplica quando se reduz a ética da empresa à análise de certas decisões freqüentes entre os homens de empresa.

Isto ocorre, em grande parte, porque a maioria dos problemas sociais não tem sua origem no que esses homens fazem mal e sim naquilo que eles deixam de fazer, isto é, nas suas omissões. Não é que resolvam mal - modo não ético - os problemas. É que são mal colocados - parcialmente, de forma míope, com horizontes estreitos - os problemas que se resolvem. Por exemplo, um êxito econômico pode ter sido conquistado com o desprezo das conseqüências sociais e ecológicas. Sem desconsiderar a validade dos resultados econômicos, interessa-nos perguntar, será que o custo social não foi alto demais? ${ }^{25}$

\section{A intuição sai na frente}

Nota-se, nesse início de década, um vislumbre de que transformações radicais se avizinham. São muitos os homens de empresa que verificam que as realidades éticas - talvez nem denominem assim, pois atuam mais por intuição - pertencem ao núcleo mais profundo e determinante das tarefas das organizações humanas que dirigem. São conscientes de que, a longo prazo, os próprios benefícios econômicos dependem mais diretamente da qualidade ética dos seus homens, do que do ambiente não controlável. Cada vez fica mais evidente que construir uma 
organização, ignorando as realidades éticas, é algo tão suicida como construir um edifício ignorando as propriedades e resistências dos materiais que se utilizam na construção.

É fundamental que a teoria avance substancialmente, uma teoria que analise as decisões humanas atendendo as dimensões - as conseqüências - éticas, psicossociológicas e econômicas da ação. Esse tratamento unificado das decisões deve ajudar a própria ética a avançar na melhor compreensão do seu objeto de estudo.

\section{Construindo uma ética gerencial}

Inicialmente temos que pensar na empresa como um sistema aberto, que recebe influências e influencia, e que López ${ }^{26}$ sintetiza da seguinte forma:

"a. o êxito das metas e objetivos econômicos dependem da adaptação da empresa às condições ambientais. O parâmetro que determina que ações conjuntas da empresa se pode prever, produzindo sua adaptação, denominaremos estratégia;

b. aquilo que determina as açoes conjuntas que é capaz de realizar uma empresa num dado momento é o que constitui seu. objeto ou competencia especifica, cujo fundamento sũo as capacidades operacionais das pessoas que forman parte da empresa;

c. o valor real que a empresa almeja realizar no mercado - clientes ou consumidores dos seus produtos ou serviços - é o que constitui a sua missão externa. A missão externa vem definida pelas necessidades humanas que a empresa procura satisfazer no seu ambiente;

d. sem uma clara consciência da missão, não é possivel o desenvolvimento de um objeto - de uma competência específica e as estratégias nâo serão mais que tentativas oportunistas de respostas aos parâmetros fixados externamente;

e. a missão externa implica necessariamente uma missão interna, que inclui a satisfação de certas necessidades e o desenvolvimento de certas capacidades tanto operacionais como afetivas nas pessoas que constituem a empresa."

Essas conclusões pressupōem a necessidade de sistemas informais para conse- guir atingir os objetivos - inclusive econômicos - das empresas. A resistência prática, para aceitá-las, é fruto de uma postura vital, cuja irracionalidade é patente: a possibilidade de obter qualquer coisa do meu interesse, de outras pessoas, através da simples aplicação do poder coercitivo.

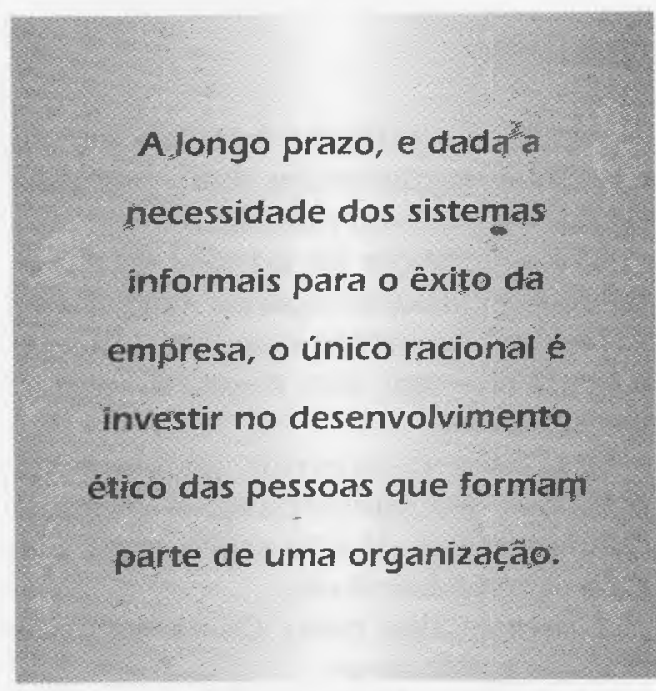

$\mathrm{Na}$ realidade, as metas coletivas podem ser obtidas: ${ }^{27}$

1. através de uma coordenaçāo formal que explicite todos os aspectos das ações individuais que são significativos para essa obtenção, unida ao suficiente poder coercitivo para motivar os sujeitos que se comportem do modo explicitamente requerido;

2. aceitando os limites práticos de qualquer sistema de controle externo e supondo que, ao menos uma parte dos resultados, se conseguirá obter através do autocontrole dos sujeitos.

A primeira possibilidade é muito mais lógica do que real. Curiosamente é o paradigma da ação humana que está implícito em todos os desenvolvimentos científicos dos últimos anos. Trata-se da hipótese mecanicista.

A segunda possibilidade gera infinitas alternativas práticas, das quais a maioria não é viável a não ser que se dê um determinado conjunto de condições. Um caso particular de alternativa inviável, na maioria das situações, é, precisamente, a alternativa ótima: aquela em que o êxito
26. Idem, ibidem, p. 49.

27. Idem, ibidem, p. 51 
das metas coletivas se consegue na base do autocontrole.

O grau de necessidade do controle externo vem determinado pela qualidade do sistema informal, que, por sua vez, é determinado pela qualidade ética dos sujeitos. E ela determina o valor social o valor para os outros - das ações que o sujeito informalmente decide executar.

\section{CONCLUSÃO}

Analisar o trabalho humano dentro das organizações exige como premissa definir o que é o ser humano.

Nossa definição foi extraída da antropologia do homem-superior: uma criatura racional de matéria e espírito - túnica e irrepetível - com uma missão de caráter transcendente.

Esse homem-superior, protagonista principal das transformações sociais a que assistimos, já não aceita viver nas ruínas da modernidade.

É preciso algo novo. Os valores modernos esgotaram-se.

As organizações, como arenas do exercício do trabalho humano, cedem a esse homem os instrumentos de realização. A organização será cada vez melhor organização, quando o homem que nela atua for cada vez mais homem. A conexão entre o desenvolvimento da qualidade ética e o êxito dos objetivos organizacionais é uma realidade.

À luz dessas considerações podemos intuir que uma autêntica "Teoria Gerencial" é, sobretudo, uma "Teoria da Liderança", que deve possibilitar a um gerente a capacidade de nos diversos campos da atividade empresarial:

1. desenhar estratégias que permitam atingir os objetivos por parte de todos os que participam da empresa;

2. desenvolver as capacidades operacionais das pessoas que trabalham na empresa de tal modo que se obtenha uma competência específica, uma capacidade de fazer bem uma série de coisas determinadas, o que constitui o objeto dessa empresa;

3. configurar e comunicar uma missão capaz de mover as pessoas pelo sentido, pelo valor, que reconhecem na sua contribuição à tarefa coletiva que realiza a empresa.

Essa liderança terá que subordinar a racionalidade econômica ao desenvolvimento humano dos subordinados. A longo prazo, e dada a necessidade dos sistemas informais para o êxito da empresa, o único racional é investir no desenvolvimento ético das pessoas que formam parte de uma organização.

\section{BIBLIOGRAFIA SUPLEMENTAR}

- DEL NOCE, Augusto. Agonia de la sociedad opulenta. Pamplona: EUNSA, 1979.

- DRUCKER, Peter F. As fronteiras da administração. São Paulo: Pioneira, 1989.

- FRANKL, Victor E. A questão do sentido em psicoterapia. Campinas: Papirus, 1990. - Psicoterapia e sentido da vida. São Paulo: Quadrante, 1986. Psicoterapia para todos. Petrópolis: Vozes, 1990.

- GOMEZ PÉREZ, Rafael. Ética empresarial teoria e casos. Madrid: Rialp, 1990. Rerpresion y Libertad. Pamplona: EUNSA. 1975.

- LLANO, Alejandro. El hombre y el trabajo: una salida ao paro antropologico. Nuestro Tiempo, n. 379-80. Pamplona: EUNSA, 1986.

. La nueva sensibilidad. Madrid: Espasa-Calpe, 1988.

- LLANO, Carlos. El trabajo directivo y el trabajo operativo en la empresa. La Vertiente Humana del Trabajo en La empresa. Madrid: Rialp, 1990.

- LÓPEZ, J.A. Pérez. El sentido de los conflitos éticos originados por el entorno en que opera la empresa. La Vertiente Humana del Trabajo en la Empresa. Madrid: Rialp, 1990. 